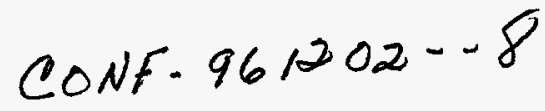

Note: This is a preprint of a paper being submitted for publication. Contents of this paper should not be quoted nor referred to without permission of the author(s).

To be submitted to the 1996 Fall MRS meeting

\title{
Optical and Structural Characterization of Zinc Implanted Silica Under Various Thermal Treatments
}

\author{
R. Mu, J. Chen, Z. Y. Gu, A. Ueda, Y.-S. Tung, and D. O. Henderson \\ Fisk University \\ Nashville, TN
}

C. W. White, J. G. Zhu, J. D. Budai, andR. A. Zuhr

Oak Ridge National Laboratory

Oak Ridge, TN

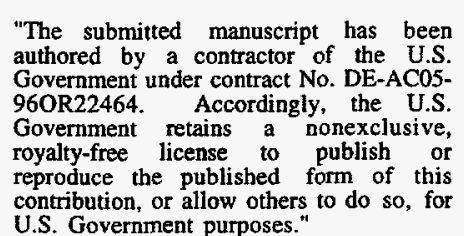

U.S. Government purposes."

Prepared by the

Oak Ridge National Laboratory

Oak Ridge, Tennessee 37831

managed by

LOCKHEED MARTIN ENERGY RESEARCH CORP.

for the

U.S. DEPARTMENT OF ENERGY

under contract DE-AC05-96OR22464
$409 \%$ ma

OSTI

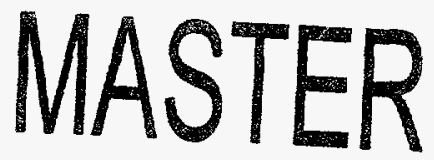

December 1996 


\section{DISCLAMMER}

This report was prepared as an account of work sponsored by an agency of the United States Government. Neither the United States Government nor any agency thereof, nor any of their employees, makes any wartanty, express or implied, or assumes any legal liability or responsibility for the accuracy, completeness, or usefulness of any information, apparatus, product, or process disclosed, or represents that its use would not infringe privately owned rights. Reference herein to any specific commercial product, process, or service by trade name, trademark, manufacturer, or otherwise does not necessarily constitute or imply its endorsement, recommendation, or favoring by the United States Government or any agency thereof. The views and opinions of authors expressed herein do not necessarily state or reflect those of the United States Government or any agency thereof. 


\section{DISCLAMIER}

Portions of this document may be illegible in electronic image products. Images are produced from the best available original document. 


\section{OPTICAL AND STRUCTURAL CHARACTERIZATION OF ZINC IMPLANTED}

SILICA UNDER VARIOUS THERMAL TREATMENTS

R. MU*, JINLI CHEN", Z.Y. GU*, A. UEDA*, Y.-S. TUNG*, D.O. HENDERSON* , C.W. WHITE $^{* *}$, JANE G. ZHU**, JOHN D. BUDAI AND R.A. ZUHR ${ }^{* *}$

${ }^{*}$ Chemical Physics Laboratory, Department of Physics, Fisk University, Nashville, TN

${ }^{* *}$ Solid State Division, Oak Ridge National Laboratory, Oak Ridge, TN

\section{ABSTRACT}

Zinc ion implanted silica with controlled thermal annealing has been investigated. Low temperature optical measurements indicate the presence of $\mathrm{Zn}$ clusters in the as-implanted silica. Optical spectra of the annealed sample under a reducing environment suggest $\mathrm{Zn}$ cluster and $\mathrm{Zn}$ metal colloid formation. The absorption peak at $\sim 5.3 \mathrm{eV}$ may be due to the surface plasma absorption of $\mathrm{Zn}$ metal colloids in silica. The oxidized samples $\left(10\right.$ and $6 \times 10^{16}$ ions $\left./ \mathrm{cm}^{2}\right)$ show an absorption peak at $\sim 4.3$ and $\sim 4.8 \mathrm{eV}$, respectively and imply $\mathrm{ZnO}$ quantum dot formation. The blueshift in exciton absorption can be attributed to the quantum confinement effects.

\section{INTRODUCTION}

It is conceivable that the study of physical and optical properties of nanophase materials assembled in various solid hosts can eventually lead to revolutionary changes in electronic, optical and telecommunication industries. However, the present understanding of nanophase materials, such as metal colloids and quantum dots, is far from comprehensive due to the complex structural, physical and optical modifications of the nanophase materials themselves from their bulk and multiplex interactions between the confining host and the confined materials. Depending upon the physical properties of the confining hosts and the nature of the confined materials, many unique mechanical, thermal and optical properties have been observed and are related to different types of confinement effects. ${ }^{1-7}$ For example, 1 ) the physical confinement, the interfacial interaction between guest and host and the reduction of the physical size of the confined particles can lead to $a$ ) hardness modification of materials $;^{1} b$ ) depression of the melting and freezing transition temperatures; ${ }^{2}$ and $c$ ) alteration of crystal nucleation and growth characteristics $;^{3}$ 2) the quantum confinement of free electrons in metals and excitons in semiconductors can result in the observation of the surface plasma resonance (SPR) and the shifts of the band gap; ${ }^{4,5} 3$ ) dielectric confinement gives rise to surface phonons observed in a wide range of nanophase materials. ${ }^{6,7}$ Due to the fact that quantum and dielectric confinement effects typically occur simultaneously it is difficult to identify the relative contributions to each of these effects.

Optical properties of $\mathrm{Zn}$ and zinc oxide materials have been well documented in literature. ${ }^{8-10}$ Zinc oxide is a typical wide band gap metal oxide semiconductor material. Like indium tin oxide (ITO), a proper doping of $\mathrm{ZnO}$ semiconductor film can result in a electrical conducting and optical transparent film, which has very important applications in flat panel display technology. In addition, the synthesized $\mathrm{ZnO}$ nanoparticles display many unique optical properties both in excitonic transitions and surface phonon modes due to the quantum confinement of excitons for small particles $\left(\mathrm{R}_{\text {(particle radius) }}<a_{\mathrm{B} \text { (Bohr cxciton radius) }}\right)^{7,8-10}$ and to the dielectric confinement from the mismatch of the diclectric functions between the host and the confined nanoparticles. ${ }^{6,7}$ 
- The effort made in the present work is first to utilize ion implantation to inject low melting metal, $\mathrm{Zn}$, into optical grade fused silica. Then, the $\mathrm{Zn}$ implanted silica substrates are thermally and laser annealed under reducing $\left(\mathrm{H}_{2}+\mathrm{Ar}\right)$ and oxidizing $\left(\mathrm{O}_{2}+\mathrm{Ar}\right)$ environments or in air to produce $\mathrm{Zn}$ metal colloids and $\mathrm{ZnO}$ semiconductor quantum dots. Optical characterizations are conducted to understand metal and metal oxide clusters and nanoparticle formation and growth kinetics. Vibrational infrared spectroscopy is used to study surface phonon modes of $\mathrm{ZnO}$ nanocrystals in a silica host. It is also intended that a controllable and a new interface may be created such as $\mathrm{Zn}$ colloids coated with a zinc oxide shell or zinc oxide quantum dots coated with a $\mathrm{Zn}$ metal shell by alternating the annealing conditions from reducing to oxidizing atmosphere and vise versa.

\section{EXPERIMENTAL}

Optical grade fused silica (Corning 7940) was used as the substrate. $\mathrm{Zn}$ ions with ion energies of $160 \mathrm{keV}$ were injected into the substrate. Based upon Rutherford Back-Scattering (RBS) measurement followed by TRIM simulation, the $\mathrm{Zn}$ ion distribution in silica substrates form almost a perfect Gausian shape with the peak position of $0.12 \pm 0.01 \mu \mathrm{m}$ below the substrate surface. Four nominal doses were implanted in silica substrates. They are $1,3,6$, and $10 \times 10^{16}$ ions $/ \mathrm{cm}^{2}$. At the peak of the Gausian, volume filling fraction of $\mathrm{Zn}$ in silica is $~ 2-3 \%$ for the highest dose.

In order to fabricate $\mathrm{Zn}$ colloids and to study the colloid formation kinetics and the properties of the ion damaged silica substrates, a stepwise (every $100^{\circ} \mathrm{C}$ ) thermal annealing process is adopted. The samples were first annealed under reducing $\left(\mathrm{H}_{2}+\mathrm{Ar}\right)$ atmosphere and then under oxidizing $\left(\mathrm{O}_{2}+\mathrm{Ar}\right)$ environment. It is expected that $\mathrm{Zn}$ metal colloids will be formed under former condition, while zinc oxide semiconductor quantum dots or the oxide coated $\mathrm{Zn}$ metal colloids will be the major products resulting from annealing in the later condition. The starting and the ending annealing temperatures were 200 and $700{ }^{\circ} \mathrm{C}$, respectively. At $700{ }^{\circ} \mathrm{C}$, a clear decrease in absorption intensity is observed indicating the loss of $\mathrm{Zn}$. Then these samples were annealed under oxidizing environment. After each step of annealing, both optical (infrared and UV-Vis) and surface (Optical and Atomic Force) microscopic characterizations were conducted to monitor the changes.

Optical measurements were made with a Hitachi 3501 UV-Vis-NIR spectrophotometer in the range of $3200-185 \mathrm{~nm}(0.38-6.7 \mathrm{eV})$ in both transmittance and reflectance modes. $0.1 \mathrm{~nm}$ spectral resolution was used for low temperature measurements and $1.0 \mathrm{~nm}$ resolution for room temperature measurements. Infrared spectra were collected with Bomem MB102 and DA3 spectrometers with a resolution of $4 \mathrm{~cm}^{-1}$.

In order to examine any possible small $\mathrm{Zn}$ cluster formation in the low dose $\mathrm{Zn}$ implanted silica, low temperature optical measurements were conducted with a Janis closed cycle CCS-300 refrigerator equipped with a Lakeshore Cryotronics 320 temperature controller. Selected samples were examined between $8-300 \mathrm{~K}$ and the temperature was controlled within $0.5 \mathrm{~K}$ for each run.

\section{RESULTS}

Fig. 1 shows the extinction UV-Vis spectra of the as-implanted optical grade silica with nominal $\mathrm{Zn}$ doses of $1,3,6$ and $10 \times 10^{16}$ ions $/ \mathrm{cm}^{-2}$. When the ion dose is higher than $3 \times 10^{16}$ ions $/ \mathrm{cm}^{2}$, a broad peak at $\sim 5.1 \mathrm{eV}$ is clearly defined. Fig. 2 displays the UV-Vis spectra of $\mathrm{Zn}$ as-implanted silica substrate at room temperature and $8 \mathrm{~K}$ with the photon energy above $5.0 \mathrm{eV}$. 


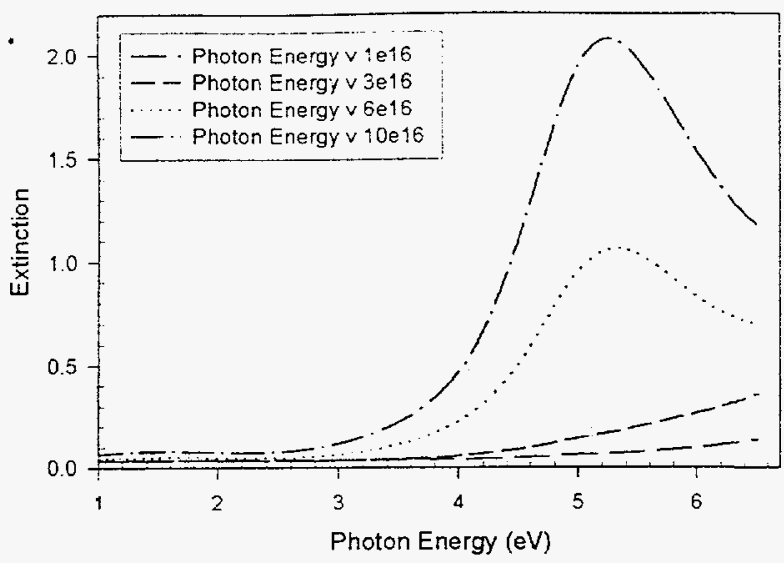

Fig. 1 Optical spectra of as-implanted silica with $\mathrm{Zn}$ concentration of $1,3,6$ and $10 \times 10^{16} \mathrm{ions} / \mathrm{cm}^{2}$.

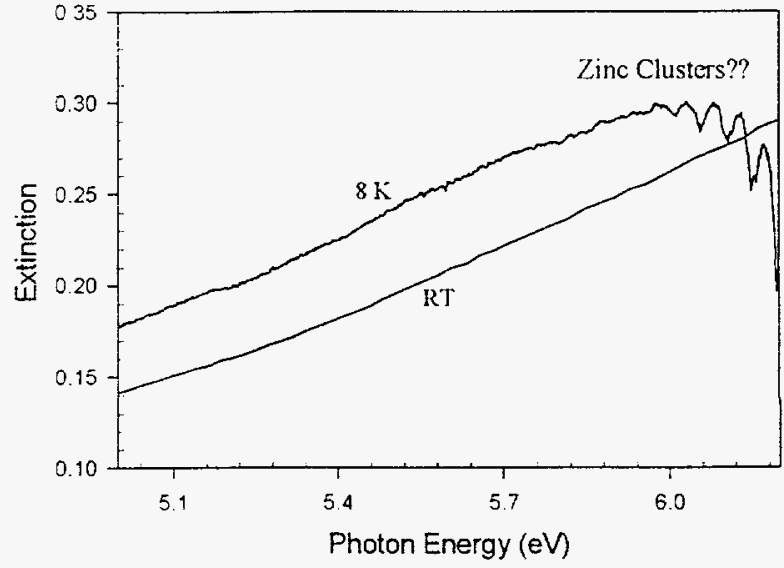

Fig. 2 Optical spectra of $\mathrm{Zn}$ implanted silica with dose of $3 \times 10^{16} \mathrm{ions} / \mathrm{cm}^{2}$ at 8 and $300 \mathrm{~K}$. A set of fine structure at photon energy $E \geq 6.0 \mathrm{eV}$ is observed.

At room temperature, the extinction spectrum is featureless. However, when the system is cooled down to $8 \mathrm{~K}$, a series spectral peaks is observed. The separation of these peaks are $\sim 2 \mathrm{~nm}$ apart. In addition, these features are only observed in $3 \times 10^{16}$ ions $/ \mathrm{cm}^{2}$ implanted samples. Fig. 3 illustrates two sets of thermally annealed $\mathrm{Zn}$ implanted samples with doses of 3 and $10 \times 10^{16}$ ions $/ \mathrm{cm}^{2}$ in a reducing atmosphere and annealed at temperatures of $300-700{ }^{\circ} \mathrm{C}$. A common feature is that as the temperature increases, the absorption cross-section between $5-6 \mathrm{eV}$ is increased. In the case of $3 \times 10^{16}$ ions $/ \mathrm{cm}^{2}$, the center peak is redshifted from $\sim 6.0 \mathrm{eV}$ down to $5.5 \mathrm{eV}$. However, an opposite spectral shift is observed for the dose of $10 \times 10^{16}$ ions $/ \mathrm{cm}^{2}$, i.e., the center peak at $-5.2 \mathrm{eV}$ is blueshifted up to $5.4 \mathrm{eV}$ as the annealing temperature is increased. Fig. 4 illustrates a set of changes in a spectra when samples were annealed under a hydrogen environment at $700^{\circ} \mathrm{C}$ and then annealed in an oxygen atmosphere. Clearly, the absorption intensity at $-5.6 \mathrm{eV}$ is decreased and the absorption at $\sim 4.3 \mathrm{eV}$ is enhanced for the dose of $10 \times 10^{16}$ sample. A similar trend is also observed for the $6 \times 10^{16}$ sample. It should be noted that the center of the intensity reduction is the same energy as the $10 \times 10^{16}$ sample, but the center of the enhanced intensity is at $4.7 \mathrm{eV}$; i.e., the center of the enhanced peak position is blueshifted as the ion dose decreases.

\section{DISCUSSION}

It is known that when silica is implanted
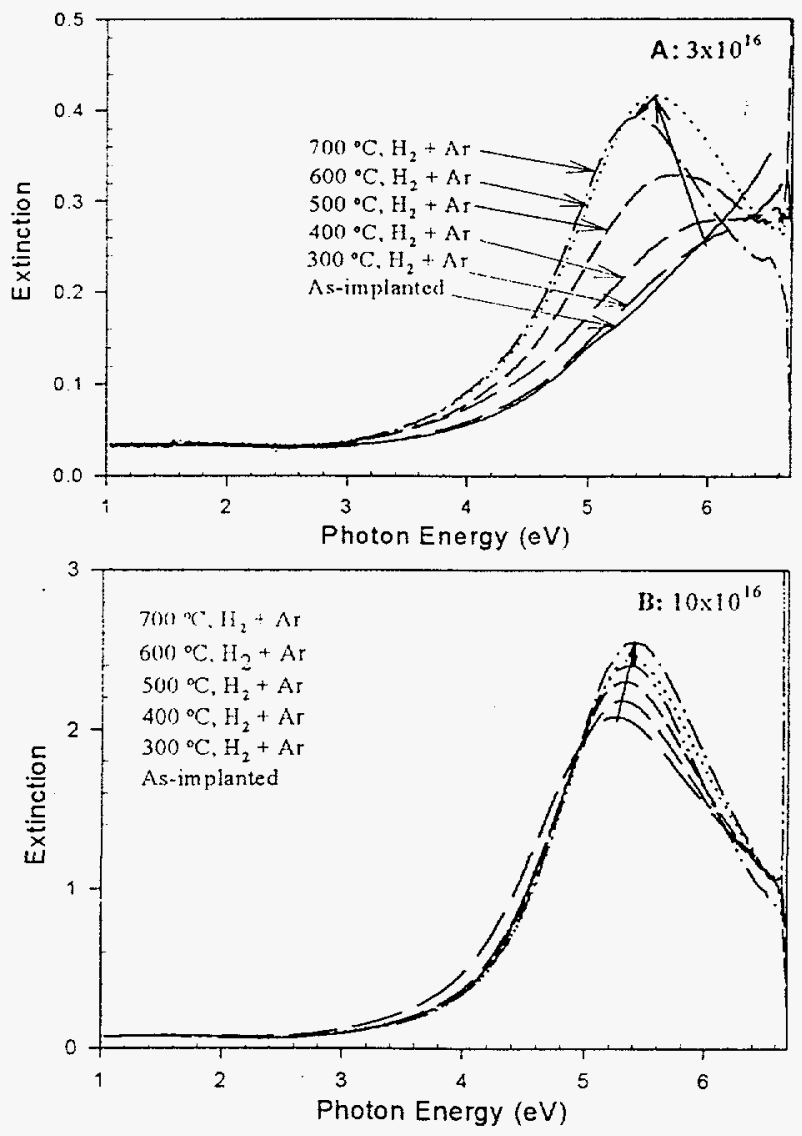

Fig. 3 Optical spectra show thermal annealing effects on $\mathrm{Zn}$ implanted fused silica under $\mathrm{H}_{2}+$ Ar environment. A) $3 \times 10^{16}$ ions $/ \mathrm{cm}^{2}$; B) $1\left(1 \times 10^{1 \mathrm{in}} \mathrm{ions} / \mathrm{cm}^{2}\right.$. 
-with energetic ions, a few bands are expected to be observed in the deep UV region, which have been attributed to the defect centers created by the energetic ions. " The creation of defect centers in a silica host has been further illustrated by EPR and infrared techniques. ${ }^{11-13}$ Therefore, it is logical to consider the ion dose dependent absorption tail near $6.2 \mathrm{eV}$ is due to the creation of the defect centers in the silica host. However, as is shown in fig. 1, the quick spreading of the absorption tail into visible region indicates that an additional optical absorption center(s) is also present. It is expected that as the $\mathrm{Zn}$ concentration increases, $\mathrm{Zn}$ clusters can also be formed. Schroder et al. ${ }^{14}$ have investigated the optical spectra of $\mathrm{Ne}$ matrix-isolated $\mathrm{Zn}_{n}(n \leq 6)$. As the concentration of the $\mathrm{Zn}$ in the Ne matrix increases, more and more absorption peaks are observed. The spreading of the absorption bands is progressively into near UV region. At the concentration of $0.002 \%$, only one strong peak is observed at $\sim 6 \mathrm{eV}$, which is attributed to $\mathrm{Zn}$ atoms. As the concentration increases, more and more absorption bands
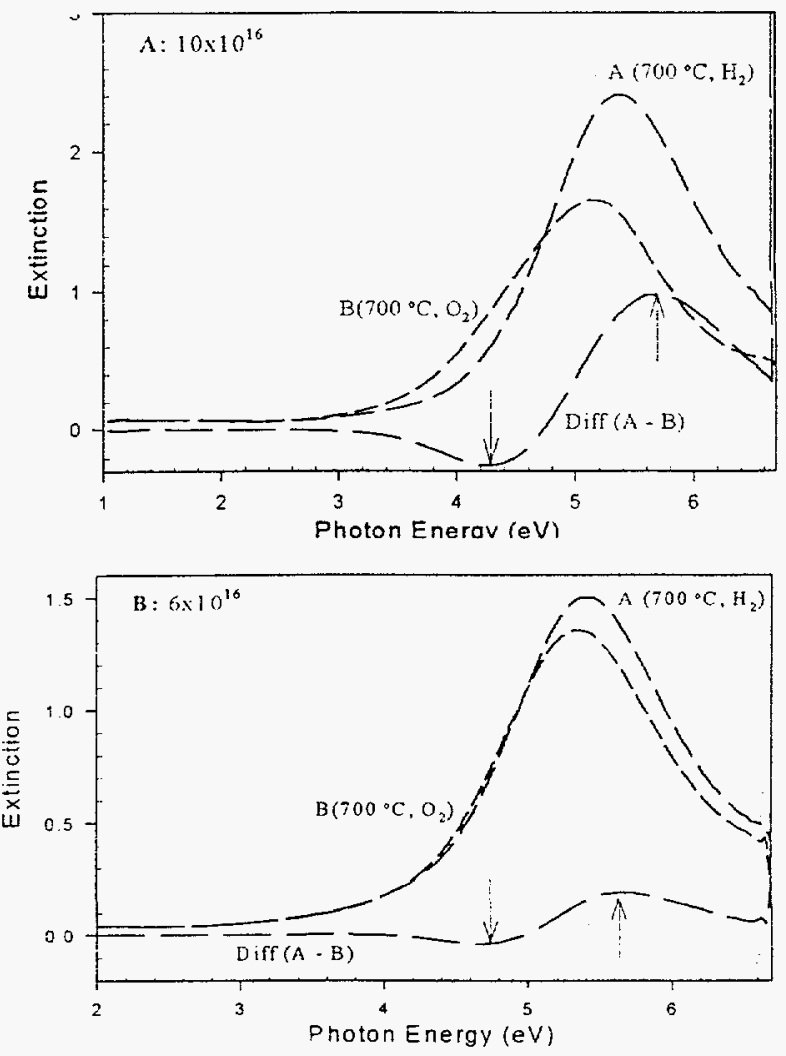

Fig. 4 Difference spectra of $\mathrm{Zn}$ implanted silica thermally annealed under $\mathrm{H}_{2}\left(700^{\circ} \mathrm{C}, 30 \mathrm{~min}\right.$.) and then annealed urder $\mathrm{O}_{2}\left(700^{\circ} \mathrm{C}, 30 \mathrm{~min}\right.$.) A) $10 \times 10^{16}$ ions $/ \mathrm{cm}^{2}$, and $\left.\mathrm{B}\right)$ $6 \times 10^{15} \mathrm{ions} / \mathrm{cm}^{2}$. are observed. At the concentrations of 2.8 and $10.2 \%$, the absorption spectra look very similar to each other and they are able to fit the spectrum at $10.2 \%$ with a linear combination of $\mathrm{Zn}_{1}-\mathrm{Zn}_{6}$ absorption spectra. Based on the RBS data from $\mathrm{Zn}$ implanted silica, the peak concentration of $\mathrm{Zn}$ at the nominal dose of $10 \times 10^{16}$ ions $/ \mathrm{cm}^{2}$ is estimated to be $\sim 3 \%$. Therefore, a similar absorption spectrum may be expected and is superimposed on to the absorption spectrum due to the defect centers in silica. For larger $\mathrm{Zn}$ clusters, a surface plasma absorption of $\mathrm{Zn}$ colloids is also expected. ${ }^{15}$ Based on Mie scattering theory, our calculation suggests a strong surface plasma absorption should occur above $3.5 \mathrm{eV}$ when the $\mathrm{Zn}$ concentration is more than $0.1 \%$. Based on the similarity of the $\mathrm{Zn}$ concentrations used in Schroder's work and our ion implanted doses, we would expect the two spectra resemble one another with exception to the ion induced defects in silica. Therefore, it is reasonable to assume that the dose dependent broad band absorption below $5 \mathrm{eV}$ can be due to both defeat centers in silica resulting from ion damage and to cluster formations of $\mathrm{Zn}$ in silica matrix.

Low temperature optical absorption measurements were also conducted. All other $\mathrm{Zn}$ doses failed to show any clear changes in the temperature range of $8-300 \mathrm{~K}$ except for the one with dose of $3 \times 10^{16}$ ions $/ \mathrm{cm}^{2}$. It is evident that fine structure can be observed when the sample is cooled down to $8 \mathrm{~K}$ as shown in fig. 2 . This structure is highly reproducible and disappears when the sample is warmed up to room temperature. Many experiments on various samples with the same and different $\mathrm{Zn}$ concentrations enable us to rule out any conceivable experimental artifacts. We can also discount the possibility that fine structure results from interference fringes. This is based on the fact that an equivalent film thickness of $6 \mu \mathrm{m}$ is required to produce the oscillations observed in UVV for the $3 \times 10^{16}$ sample (an index of 1.5 was used for the calculation). We, 
therefore, conclude that the sharp peaks observed at low temperature are due to the sample itself and tentatively attributed them to absorption of $\mathrm{Zn}$ clusters. However, more experiments are required to confirm this speculation. It is also conceivable that the sharp peaks could be due to vibrational fine structure that is resolved in the electronic transition at low temperature. In the latter case, we have to assume that the electronic transition peak is above $6.6 \mathrm{eV}$ so that the stronger absorption phonon bands peaks are the low order.

Thermal annealing at temperatures of $300-700{ }^{\circ} \mathrm{C}$ under $5 \% \mathrm{H}_{2}+95 \% \mathrm{Ar}$ further supports the idea of $\mathrm{Zn}$ cluster formation in the as-implanted samples shown in fig. 1 . It is known that thermal annealing at high temperature can eliminate defect centers created by ion implantation in silica. If the absorption below $4.5 \mathrm{eV}$ was Solely due to these defects resulting from ion damage, then one would have observed a progressive decrease in absorption since more and more defeats are thermally removed. ${ }^{11,12}$ This is also supported by our infrared reflectance spectra of the ion implanted silica. However, our observation is to the contrary. As the temperature and thermal annealing time are increased, the absorption intensity is enhanced and the peak position is redshifted. As pointed out earlier, $\mathrm{Zn}$ metal colloids and small clusters can absorb photons in $4-6 \mathrm{eV}$. Therefore, it is believed that the increase in intensity upon annealing is primarily due to the formation of $\mathrm{Zn}$ clusters and metal colloids. By comparing the dose and temperature dependent thermal annealing results in fig. 3, the redshift $\left(3 \times 10^{16}\right.$ ions $\left./ \mathrm{cm}^{2}\right)$ and the blueshift $\left(10 \times 10^{16}\right.$ ions $\left./ \mathrm{cm}^{2}\right)$ of the absorption peak suggest $\mathrm{Zn}$ colloid formation in silica. In addition, the surface plasma of the $\mathrm{Zn}$ metal colloids is located at $\sim 5.3 \mathrm{eV}$. The redshift for lower dose of $3 \times 10^{16}$ ions $/ \mathrm{cm}^{2}$ is mainly due to the transition from $\mathrm{Zn}$ cluster to metal colloids, while the blueshift for higher dose of $10 \times 10^{16}$ ions $/ \mathrm{cm}^{2}$ is predominantly due to the reduction of the defect centers in the host materials.

When the samples are annealed under a reducing atmosphere and further treated under oxidizing environment at $700^{\circ} \mathrm{C}$, a clear spectral band shift is observed. The these spectra, as illustrated in fig. 4, clearly show that an additional peak at $\sim 4.3$ and $\sim 4.7 \mathrm{eV}$ has developed with the expense of the intensity at $\sim 5.6 \mathrm{eV}$ for the $\mathrm{Zn}$ doses of 10 and $3 \times 10^{16}$ ions $/ \mathrm{cm}^{2}$, respectively. It can be argued that when the samples are annealed under an oxygen environment, some of the $\mathrm{Zn}$ clusters and colloids may be oxidized and eventually form $\mathrm{ZnO}$ quantum dots. The physical size of these $\mathrm{ZnO}$ quantum dots can be closely related to the size of the $\mathrm{Zn}$ metal colloids. It is also know that the band gap of $\mathrm{ZnO}$ semiconductor is $\sim 3.4 \mathrm{eV}$ and its Bohr exciton radius $a_{\mathrm{B}}=2.5 \mathrm{~nm} .{ }^{16}$ It is also known that when the physical size of quantum dots is comparable or smaller than the exciton radius $a_{\mathrm{B}}$, their exciton absorption is blueshifted, which can be qualitatively predicted by EMA theory. ${ }^{17}$ With these considerations, it is logical to consider that the physical size of the $\mathrm{ZnO}$ quantum dots formed in higher dose $\left(10 \times 10^{16}\right.$ ions $\left./ \mathrm{cm}^{2}\right)$ is larger than that of the lower dose $\left(6 \times 10^{16}\right.$ ions $\left./ \mathrm{cm}^{2}\right)$ and consequently the absorptions at $\sim 4.3$ and $\sim 4.7 \mathrm{eV}$ for the oxidized samples ( 3 and $10 \times 10^{16}$ ions $/ \mathrm{cm}^{2}$ ) are due to the exciton absorption of the $\mathrm{ZnO}$ quantum dots in the silica host.

\section{CONCLUSION}

Optical characterization of $\mathrm{Zn}$ ion implantation in optical grade silica with four nominal doses of $1,3,6$ and $10 \times 10^{16}$ ions $/ \mathrm{cm}^{2}$ with and without thermal treatments has been conducted. The strong optical absorption below $4.5 \mathrm{eV}$ for the as-implanted samples is attributed both to defect centers in silica due to the ion implantation and to $\mathrm{Zn}$ clusters formed in silica. A set of absorption peaks at $8 \mathrm{~K}$ at photon energy $E \geq 6.0 \mathrm{eV}$ may be due to $\mathrm{Zn}$ cluster formation and/or vibrational fine structure of these clusters. Thermal annealing under $5 \% \mathrm{H}_{2}+95 \% \mathrm{Ar}$ shows the intensity cnhancement at $\sim 5.3 \mathrm{cV}$, which can be attributed to $\mathrm{Zn}$ cluster and metal colloid 
-absorption. Oxygen annealed samples show a new band developed at $\sim 4.3$ and $\sim 4.8 \mathrm{eV}$ and a decrease of intensity at $\sim 5.6 \mathrm{eV}$ for the doses of 6 and $10 \times 10^{16} \mathrm{ions} / \mathrm{cm}^{2}$ suggesting possible $\mathrm{ZnO}$ quantum dot formation. The blueshift of the exciton absorption for the lower dose from 4.3 to $4.8 \mathrm{eV}$ is due to the stronger quantum confinement effects as predicted by EMA theory.

\section{ACKNOWLEDGMENTS}

Authors wish to acknowledge the supports from DOE under grant DE-FG05-94ER45521 at Fisk and contract DE-AC05-84OR21400 with Lockheed Martin Energy System at Division of Materials Science, ORNL.

\section{REFERENCES}

1. for example: R. W. Siegel, IV International Conference on Advanced Materials, IUMRSICAM 95, Cancun Mexico, Aug. 27 - Sept. 1995.

2. M.B. Ritter, D.D. Awschlam, W.M. Shafer, Phys. Rev. Lett. 61, 966 (1988); J. Warnock, D.D. Awschalom, M.W. Shafer, Phys. Rev. Lett. 57, 1753 (1986); R. Mu, F. Jin, S.H. Morgan, D.O. Henderson and E. Silberman, J: Chem. Phys. 100, 7749 (1994); R. Mu and V.M. Malhotra, 44, 4296 (1991).

3. R. Mu, Y. Xue and D.O. Henderson, Phys. Rev. B 53, 6041 (1996); R. Mu, Y.S. Tung, A. Ueda and D.O. Henderson, J. Phys. Chem. [in print] (1997).

4. P. Mulvaney, Langmuir 12, 788 (1996).

5. J.A.A.J. Perenboom, P. Wyder and F. Meier, Phys. Rep. 78, 173 (1981).

6. S. Hayashi, Jpn. J. Appl. Phys. 23, 665 (1984), and references therein.

7. C.W. White, J.D. Budai, J.G. Zhu, S.P. Withrow, D.M. Hembree, Jr., D.O. Henderson, A. Ueda, Y.S. Tung, R. Mu, R.H. Magruder, J. Appl. Phys. 79. 1876 (1996); R. Mu, D.O. Henderson, Y.S. Tung, A. Ueda, C. Hall, W.E. Collins, C.W. White, R.A. Zuhr and Jane G. Zhu, J. Vac. Sci. Technol. A 14, 1482 (1996).

8. D.W. Bahnemann, C. Kormann and M.R. Hoffmann, J. Phys. Chem. 91, 3789 (1987).

9. M. Haase, H. Weller and A. Henglein, J. Phys. Chem. 92, 482 (1988), and references therein.

10. S. Mahamuni, B.S. Bendre, V.J. Leppert, C.A. Smith, D. Cooke, S.H. Risbud and H.W.H. Lee, NanoStru. Mat. 7, 659 (1996).

11. R. A. Weeks, in Glasses and Amorphous Materials, edited by J. Zarzicki, Chap. 6 pp311- 373 (Wiley, New York, 1992); S. Y. Park, R. A. Weeks, and R. A. Zuhr, J. Appl. Phys. 77, 6100 (1995). 12. D. O. Henderson, M. A. George, Y. S. Tung, R. Mu, A. Burger, S. H. Morgan, W. E. Collins, C. W. White, R. A. Zuhr, and R. H. Magruder IIl, J. Vac. Sci. Technol. A 13, 1254 (1995); D. O. Henderson, S. H. Morgan, R. Mu, W. E. Collins, R. H. Magruder, C. W. White, and R. A. Zuhr, Mat. Res. Soc. Symp. Proc. 316, 451 (1994).

13. H. Hosono, J. Appl. Phys. 69, 8079 (1990); R. A. B. Devine, J. Non-cryst. Solids 152, 50 (1992).

14. W. Schroder, H. Wiggenhauser, W. Schrittenlacher and D.M. Kolb, J. Chem. Phys. 86, 1147 (1987).

15. J. A. Creighton and D. G. Eadon, J. Chem. Soc. Faraday Trans. 87, 3881 (1991).

16. G. Redmond, A. O'Keeffe, C. Burgess, C. MacHale and D. Fitzmaurice, J. Phys. Chem. 97, 11081 (1993).

17. A. I. Ekimov, A. L. Efros, A. A. Onushchenko, Solid State Commun. 56, 921 (1985); L. E. Brus, J. Chem. Phys. 80, 4403 (1984). 